\title{
BMI open Is lack of suitable housing a barrier to home-based dialysis therapy for patients with end-stage renal disease? A cohort study
}

\author{
Suzanne H Forbes, Kieran McCafferty, Trevor Lawson, Meagan Stoby-Fields, \\ Martin Raftery, Muhammad Magdi Yaqoob
}

To cite: Forbes SH, McCafferty K, Lawson T, et al. Is lack of suitable housing a barrier to homebased dialysis therapy for patients with end-stage renal disease? A cohort study. BMJ Open 2013;3:e002117. doi:10.1136/bmjopen-2012002117

- Prepublication history and additional material for this paper are available online. To view these files please visit the journal online (http://dx.doi.org/10.1136/ bmjopen-2012-002117).

\section{- Additional material is published online only. To view please visit the journal online (http://dx.doi.org/10. 1136/bmjopen-2012- 002117).}

Received 17 September 2012 Accepted 9 January 2013

This final article is available for use under the terms of the Creative Commons Attribution Non-Commercial 2.0 Licence; see http://bmjopen.bmj.com

Department of Nephrology, Royal London Hospital, London, UK

Correspondence to Professor Muhammad Magdi Yaqoob; m.m.yaqoob@qmul. ac.uk, magdi.yaqoob@ bartshealth.nhs.uk

\section{ABSTRACT}

Objective: To determine whether inadequate housing is the main barrier to the provision of home dialysis treatment.

Design: Prospective observational study.

Participants: All patients attending a predialysis clinic between 2006 and 2009 deemed medically suitable for home dialysis and not active on the preemptive transplant list.

Setting: A predialysis clinic in a London teaching hospital.

Main outcome measure: Assessment of patient's accommodation for suitability for home-based dialysis using departmental guidelines and the Government's Housing Health and Safety Rating System regulations 2005.

Results: A lack of adequate housing prohibited the provision of home haemodialysis to all but one of these patients. Moreover, only $29 \%$ of homes assessed were suitable for peritoneal dialysis, despite the lower spatial demands of this form of renal replacement therapy. In addition to the specific requirements of dialysis, we also found that only $33 \%$ of the homes visited fulfilled the minimum standard of housing as defined in the Government's Decent Homes Standard, with multiple specific hazards identified across the properties.

Conclusions: This study illustrates that the lack of suitable housing is a major barrier to the provision of home-based dialysis and underscores the need for this to be addressed urgently at both the central government and local authority levels. We suggest that it should be considered as a major priority to rehouse medically suitable patients with a view to enabling home-based therapy.

\section{INTRODUCTION}

In 2009, the number of incident renal replacement therapy (RRT) patients in the UK was 6730 , with a total of 49080 prevalent adult patients receiving some form of RRT, broadly split as $52 \%$ undergoing dialysis and

\section{ARTICLE SUMMARY}

Article focus

- National Institute of Clinical Excellence recommends that all suitable predialysis patients should have the option of home-based dialysis.

- Only $18 \%$ of incident dialysis patients dialyse at home.

- This study set out to examine factors preventing patients from opting for home-based renal replacement therapy (RRT), with a particular emphasis on assessing environmental factors that precluded their suitability.

Key messages

- Less than $0.5 \%$ of homes assessed were suitable for home haemodialysis.

- Only $29 \%$ of homes assessed were suitable for peritoneal dialysis.

- In total, $67 \%$ of homes assessed failed the Government's minimum housing standards.

Strengths and limitations of this study

- This is a prospective study with a clearly defined population.

- The study was performed within a single centre serving an ethnically diverse population which may not be representative of all areas in the UK.

- Nonetheless, these important findings are still relevant to over 6000 patients who start RRT every year in the UK.

$48 \%$ with a functioning renal transplant. ${ }^{1}$ These figures are increasing by over $3 \%$ a year each year. Indeed, the incidence of endstage renal disease (ESRD) in the UK is higher than that of many highly publicised malignancies such as multiple myeloma and cervical cancer.

Home dialysis refers to providing dialysis either by home haemodialysis (HHD) or peritoneal dialysis (PD) in the patient's own home.

In 2002, the National Institute of Clinical Excellence UK guidelines suggested that all 
suitable patients should be offered the choice of HHD or haemodialysis in a hospital or satellite unit. Their assumption was that up to $15 \%$ of all haemodialysis patients in the UK would be suitable for home-based treatment. ${ }^{2}$ This form of treatment provides flexibility, independence from hospital, adaptability around employment and by virtue of much reduced transport requirements is environment friendly. It is also associated with better outcomes and is more cost-effective than in-centre or satellite-based haemodialysis. ${ }^{13}$

In reality what was seen, until relatively recently, was a steady decline in HHD treatment. The peak in HHD occurred in 1983 when 59\% of haemodialysis patients dialysed in their own homes. There followed a continuous decline in the number of patients on home-based haemodialysis until 2003, at which point the numbers plateaued. No doubt this is reflected by an increased uptake of PD throughout the 1990s, an increase in hospital-based renal centres, in particular, satellite units and an increase in the number of patients with a functioning renal transplant, as well as a general change in the demographics of patients accepted to long-term RRT. The prevalence of HHD has increased slightly in recent years, which is especially seen when comparing figures from 2008 to 2009 , but still only 645 patients in total received HHD (3\% of all prevalent dialysis patients) in 2009. At present, the number of patients on HHD varies from centre to centre and, in part, will reflect differences in renal unit culture. Across the UK, HHD figures range from $0 \%$ to $11.2 \%$ of all $\mathrm{HD}$ patients. Very few units in the UK-six in total-have more than $5 \%$ of their dialysis patients on HHD. In terms of $\mathrm{PD}$, the figures are also variable, depending on the local centre, but nationally in 2009 PD modalities made up $15.1 \%$ of the prevalent dialysis cohort, with continuous ambulatory peritoneal dialysis (CAPD) accounting for $8.1 \%$ and automated PD (APD) for $7 \%{ }^{1}$

Barriers to home-based dialysis include patient frailty and comorbidity, frequent changes of address, lack of a potential partner or carer at home for support in case of emergency and inadequate housing.

With this in mind, we set out to examine factors preventing patients from opting for home-based RRT, with a particular emphasis on assessing environmental factors that precluded their suitability.

\section{METHODS}

We performed a prospective audit of the predialysis assessment home visits of 249 patients who were deemed medically suitable for home dialysis from 2006 to 2009. Patients who were expected to receive a pre-emptive transplant were excluded. The study cohort represented $40 \%$ of the incident RRT population during this period in a tertiary renal unit serving a large and diverse inner city population in East London. The ethnicity of our patients, as reported in the most recent Renal Registry report, was made up of approximately one-third white, one-third black and one-third south Asian. This is in comparison with $78.1 \%$ white, $7.4 \%$ black and $12.3 \%$ south Asian across the rest of England. There is, of course, great variation across the UK with some reporting $0 \%$ ethnic minorities and others, including our own centre, other London centres and Bradford, reporting over $50 \%$ ethnic minorities. Up to $66 \%$ of the RRT patients in our programme are from ethnic groups despite the catchment area comprising approximately one million whites and half a million each of south Asians and people of black ancestry. This reflects the well recognised high incidence of ESRD in ethnic groups. ${ }^{4}$ The median age of patients undergoing RRT in our centre is also slightly younger than that seen across the country with the median age being around 57 years as opposed to just over 63 years in tertiary centres in general. ${ }^{1}$ The younger age of our cohort reflects a higher proportion of first generation immigrant population in our catchment area.

All patients undergoing a home assessment visit had already been deemed medically suitable to receive home-based RRT using the MATCH-D criteria. ${ }^{5}$

MATCH-D is a US-based method used in assessing treatment choices for home dialysis. It was developed to help nephrologists to identify and assess those patients who would be suitable for home-based therapies and utilises a three-tier approach for assessing patients. The first tier is a list of triage criteria for patients who should be dialysing at home, including patient choice and ability, various lifestyle factors including employment and certain medical factors such as fluid and blood pressure control, or the desire to become pregnant. If the outcome of this triage is positive, it suggests that these patients should be strongly encouraged to pursue home-based treatment. The second tier suggests solutions for common barriers that prevent home treatment such as patient education, resolution of hygiene issues, space for supplies and quality of water supply. The final tier presents contraindications to home dialysis listing environmental problems such as homelessness, no or unreliable electricity supply, a home which is a health hazard and patient factors such as uncontrolled psychosis or seizure disorder, brain damage or dementia, resulting in reduced awareness or ability to report symptoms. Thus, in the latter two tiers, there are clear references to environmental factors, and we focused our investigation on these areas.

At each home visit, several factors were assessed that were relevant to home-based dialysis. These included spatial factors, housing type and condition, accessibility to the property and, finally, public health and hygiene factors. Initially, a statutory Housing assessment was required under the Housing Health and Safety Rating System (HHSRS) (England) Regulations 2005, which lists 29 factors which must be fulfilled as the minimum criteria for the home to be deemed fit for human habitation. ${ }^{6}$ It should be noted that these regulations are quite explicit, user-friendly and do not require formal training. The HHSRS consolidates what was previously a 
wide range of complex housing and public health legislation into a very understandable matrix. Our own checklist is very easy to use. We also make much use of photographic evidence which can facilitate applications for rehousing/remedial/enforcement action with Local Authorities and Community Health Services. This system could easily be used by other units, in which case it could provide real-time evidence nationally in respect of medical housing needs (see online supplementary appendix for full HHSRS and DHS documents, which are the statutory national assessment guidelines, as well as a copy of the crib sheet used for each home assessment). Thereafter. we looked at requirements specific to the different modalities of home dialysis.

Requirements for HHD included a separate room with a bed or a couch, a clear space of at least $6^{\prime} \times 6^{\prime}$ $(1.8 \mathrm{~m} \times 1.8 \mathrm{~m})$, ideally adjacent to a mains water supply, with an external drain pipe and a minimum ceiling height of $8^{\prime}(2.4 \mathrm{~m})$. The water supply had to be capable of providing at least $40 \mathrm{l} / \mathrm{h}$ directly from the mains supply and with the appropriate water pressure. There was also a requirement for a total unallocated space (preferably within the accommodation) of $6^{\prime} \times 6^{\prime}$ $(1.8 \mathrm{~m} \times 1.8 \mathrm{~m})$ for storage of consumables and disposables. Due to siphoning and suction problems, HHD does not work well in the upper floors of tower blocks. Elevation of the accommodation was not specifically considered as a significant factor in the determination of general housing suitability. For APD, the spatial requirements were lesser, requiring sufficient space of $2.8^{\prime} \times 2.8^{\prime}$ $(0.85 \mathrm{~m} \times 0.85 \mathrm{~m}) \quad$ (preferably in the bedroom), to accommodate an APD machine and a total unallocated space (preferably within the accommodation) of $5^{\prime} \times 5^{\prime}$ $(1.5 \mathrm{~m} \times 1.5 \mathrm{~m})$ for dialysate and disposables. Finally, for CAPD, there needed to be sufficient space $\left(4^{\prime} \times 4^{\prime}\right.$ $(1.2 \mathrm{~m} \times 1.2 \mathrm{~m})$ to accommodate a sitting person doing a PD exchange with the same total unallocated storage space as for APD. Both PD modalities required access to either a sink or a drain. For accessibility, there was a requirement for a working lift, or the accommodation had to be on a low level. In some circumstances, the installation of APD/CAPD necessitated some marginal inconvenience to the occupants of the household; for example, risk of tripping or falling hazards, compromised escape routes and exacerbation of overcrowding. Such houses were considered barely suitable for APD/ CAPD, although treatment did proceed.

\section{RESULTS}

The demographics of patients assessed are set out in table 1 . They represented a broad range of ages and races, typical of the population that our renal unit serves. First, the occupant's home was assessed against the Government's Decent Homes Standard, and it was found that only $33 \%$ of the homes visited fulfilled this minimum standard. It was then assessed as to whether there were any factors in the home which were hazardous to their health

\begin{tabular}{ll} 
Table $1 \quad$ Patient demographics & \\
\hline Sex & \\
Male & $141(57 \%)$ \\
Female & $108(43 \%)$ \\
Age (median (IQR)) & $53(40-68)$ \\
Range & $22-90$ \\
Race & \\
White & 65 \\
Black & 82 \\
Indo-Asian & 84 \\
Chinese & 5 \\
Other & 13 \\
Diabetic & \\
Yes & $94(38 \%)$ \\
\hline
\end{tabular}

and well-being, as defined in the Government's HHSRS (England) Regulations 2005. ${ }^{6}$ These regulations comprise 29 specific hazards which range widely from damp and mould growth to overcrowding and lack of space, to inadequate facilities for maintaining personal hygiene, sanitation, drainage and risk of structural collapse of the building. For the purposes of this report, up to four hazards were listed for any one home at the time of visit. These are summarised in table 2.

Table 2 Hazards scored according to the Housing Health and Safety Rating System regulations (England) 2005

\begin{tabular}{lc}
\hline Hazard & $\begin{array}{c}\text { Number of homes } \\
\text { scoring (\%) }\end{array}$ \\
\hline $\begin{array}{l}\text { Overcrowding and lack of space } \\
\text { Damp and mould growth }\end{array}$ & $143(57.4)$ \\
Inadequate facilities for maintaining & $43(32.5)$ \\
personal hygiene, sanitation and & \\
drainage & \\
$\begin{array}{l}\text { Risk of structural collapse and } \\
\text { falling elements of the building }\end{array}$ & $24(9.6)$ \\
$\begin{array}{l}\text { Inadequate domestic hygiene, pests } \\
\text { and refuse }\end{array}$ & $20(8)$ \\
$\begin{array}{l}\text { Inadequate facilities for storing and } \\
\text { preparing food }\end{array}$ & $20(8)$ \\
$\begin{array}{l}\text { Inadequate supply of } \\
\text { uncontaminated water }\end{array}$ & $9(3.2)$ \\
$\begin{array}{l}\text { Electrical hazards } \\
\text { Falls associated with bathing/ } \\
\text { washing/toileting }\end{array}$ & $8(3)$ \\
$\begin{array}{l}\text { Risk of falling on stairs } \\
\text { Excess heat }\end{array}$ & $6(2.4)$ \\
$\begin{array}{l}\text { Lead } \\
\text { Risk of falling on level surfaces } \\
\text { Asbestos and MMF (manufactured } \\
\text { mineral fibres) }\end{array}$ & $1(2)$ \\
$\begin{array}{l}\text { Risk of falling between levels } \\
\text { Carbon monoxide and fuel } \\
\text { combustion products }\end{array}$ & $1(0.4)$ \\
$\begin{array}{l}\text { Position and operability of } \\
\text { equipment/amenities } \\
\text { Uncombusted fuel gas }\end{array}$ & $1(0.4)$ \\
& $1(0.4)$ \\
& $1(0.4)$ \\
& $1(0.4)$ \\
\hline
\end{tabular}


We also noted whether the premises were let by a private landlord or to a local authority for use as temporary accommodation for homeless families and found that 171 of the homes visited $(69 \%)$ were such houses.

In terms of assessing suitability for home-based therapy, from these consecutive 249 home assessments we found that $70 \%$ were not suitable for either PD or HHD. Only $29 \%$ were deemed barely suitable for PD on spatial grounds. The reason for homes being unsuitable related entirely to spatial and health and safety concerns. Our experience is that although many families will accept compromises to their quality of life and lifestyles to facilitate the spatial demands of home RRT, these can seriously impact those particularly in overcrowded or poor quality accommodation and substantially increase the potential for accident and injury. Hence our 'barely suitable' category. We strive for the best for our patients and their families and aim to ensure that their safety is not compromised by the home dialysis process. However, during the period of the study, we had a case of a 5-year-old child, who sustained serious head injuries when a large stack of PD boxes collapsed upon him, and various cases of sequential joist failure resulting in floor collapse due to floor loadings being exceeded due to the weight of PD storage. Just one home visit resulted in a patient being considered for and starting home haemodialysis (see figure 1).

\section{DISCUSSION}

The idea of home-based dialysis treatment is not new. Several groups claim to have been the first to start HHD, including Shaldon in 1964 in the Royal Free Hospital and Nose (Haikado group) in his $\mathrm{PhD}$ thesis of 1962. ${ }^{4} 8$ In addition, Boen $e t a l^{9}$ set up a PD programme in 1960 that was designed to allow people to dialyse at home.

RRT consumes $1-2 \%$ of the total National Health Service budget (although ESRD only affects $0.05 \%$ of the general population), so in addition to patient choice there are also financial implications in the choice of RRT for patients with ESRD. ${ }^{1}$ In the current financial

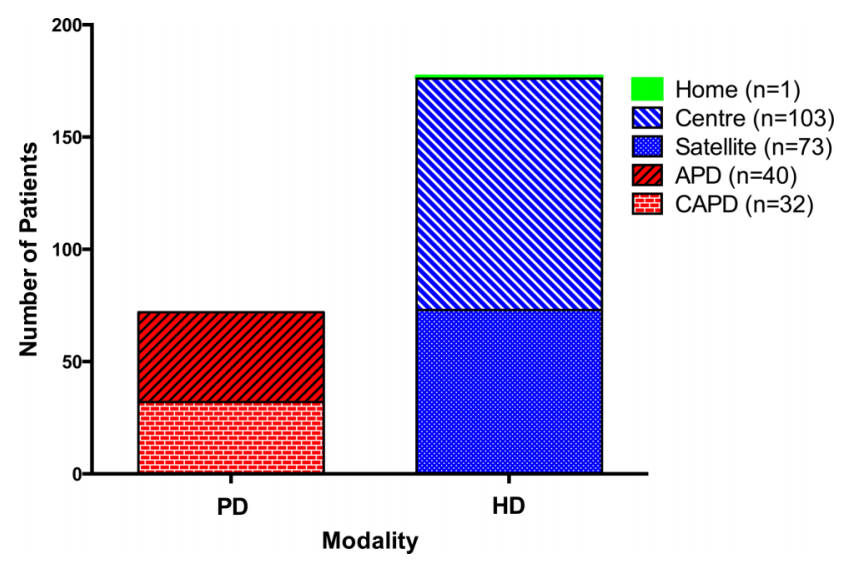

Figure 1 Dialysis modality following home visit. climate, the department of health working unit has encouraged home-based treatment as being potentially both more cost effective and providing better outcomes. Studies looking at both the physiological and financial benefits of home-based RRT have suggested that HHD provides more treatment hours at a lower cost. In addition, CAPD ( $£ 15570$ mean annual cost) is widely recognised to be the most cost-effective modality of RRT, followed by HHD (£20 764) and APD (£21 655), compared with either satellite (£32 669)-based or hospital (£35 023)-based haemodialysis. ${ }^{10}$

In addition to the financial argument, it is clear that home-based dialysis confers many wider advantages over hospital-based treatment in suitable patients. ${ }^{11}$ It offers greater autonomy for patients, giving them increased independence, responsibility and confidence and an enhanced quality of life. ${ }^{12} 13$ More importantly, it reduces the considerable costs and environmental impact of 156 round trips to their dialysis centre, and it must be emphasised that the quoted costs for centre and satellite haemodialysis do not include transport costs. It is notable that the reduced carbon footprint due to reduction in patient transportation, however, may be offset by the increased frequency of home haemodialysis sessions. ${ }^{14}$ In addition, HHD provides the patient with sufficient flexibility to schedule their dialysis such that employment prospects are not adversely affected and younger, fitter patients are able to hold down fulltime employment. There is also evidence that, at least in the case of HHD, it offers an opportunity for better rehabilitation and lower infection risks. Ultimately, it contributes to better long-term survival. ${ }^{15}$ In addition, there is evidence that short daily or nocturnal sessions of haemodialysis can result in improved blood pressure control, reduced left ventricular mass, better control of anaemia and hyperphosphataemia and more effective removal of middle molecular weight substances. ${ }^{16-21}$ Yet it is underused both in the UK and globally. ${ }^{22}$

Previously, multiple reasons have been suggested for the reduction in the use of home dialysis, including an older dialysis population, with a greater burden of comorbidities, especially diabetes. Inadequate patient education, limited exposure of nephrologists, nursing staff and social workers to home-based therapies and lack of available programmes have also been mooted as reasons for the decline. ${ }^{23}$

We have demonstrated, however, that even with a willing clinical team and an existing home therapy programme within a large teaching hospital serving an inner city population, the use of either HHD or PD is not a viable option for the majority of medically suitable patients.

This study highlights that the single most important barrier to achieving higher rates of home-based treatment among medically appropriate dialysis patients is the suitability of their home environment. It is apparent that there is a considerable and increasing shortage of appropriate housing, even to support the relatively low 
spatial requirements of PD. Indeed, within our cohort, there was only one home suitable to support home haemodialysis. In a poor inner city environment, it is clear that despite up to $40 \%$ of incident RRT patients being suitable medically for home dialysis, the condition of the housing stock is such that this form of treatment is precluded in the vast majority of instances. With the increasing housing demands in such an area, influenced by the changing demographic, single occupancy households, the economic climate and the new social welfare bill passed in parliament, the reality is that the ability to offer home-based treatments will be further compromised. In fact, there is already evidence that our catchment area is facing the biggest housing crisis since the 1930s with many households classified as overcrowded, a significant number of homes classified as unfit for human habitation and many affordable new homes, which were scheduled to be built, abandoned due to budget cuts. Already 35920 families in London are in temporary accommodation, while an estimated 207000 households in the capital are 'statutorily overcrowded' (comprising around $7 \%$ of London households, and as compared with 630000 households throughout England), around half of which are social rented housing. ${ }^{24-26}$ Although London and Scotland have a significantly higher proportion of overcrowded houses than any other region in the UK, with $17 \%$ and $12 \%$, respectively, overcrowding does remain a significant problem across the country, averaging approximately $5 \%$ of households nationally. ${ }^{27}$

A similar picture exists nationwide with regard to suitability of housing stock. Currently, over $33 \% \quad$ (7.4 million) of English homes do not meet the UK Government 'Decent Homes Standard', while a further 4.8 million homes were identified to be potentially seriously hazardous to their occupants. ${ }^{25} 2829$ Regionally, the proportion of homes in England classified as nondecent varies from about $40 \%$ in the south-west to less than $25 \%$ in the north-east, with London in the middle of the range at $33 \% .{ }^{30}$ The proportion of non-decent homes is significantly higher in rural areas, where approximately $50 \%$ of homes in the most rural areas are classified as non-decent, compared with about $30 \%$ in small towns and urban areas. ${ }^{30}$

The criteria used in the current study to assess the suitability of houses for home-based RRT could be viewed by some as too rigid. However, despite using the definitions of the evaluation tools with flexibility and common sense, many houses still failed on the bare minimum criteria of decent living standards. In fact, there is little in the way of national or international guidelines regarding the exact environmental standards necessary for home-based dialysis. Neither is there any set national methodology with regard to housing assessment for RRT, who this is done by or if it needs to be done at all. Some units do not assess any homes, whereas some assess some homes based upon their own local criteria. Perhaps the development of national documents and standards would more clearly define the necessary requirements and the process of assessing homes, thus facilitating the start of home-based therapy, or indeed aid in the process of rehousing in appropriate circumstances.

These statistics have obvious negative implications for the growth of home-based dialysis treatment as the ideal form of the UK RRT for suitable patients. It would appear that the UK Government's desire to substantially increase home dialysis provision and, specifically, HHD provision may be unrealistic with the current housing stock throughout the UK. Our findings are applicable to many parts of the country.

Poverty, social deprivation and differences in ethnicity between rural and urban populations lead to a greater demand for renal services in urban areas throughout the UK, not just in London. Moreover, the healthcare challenges associated with the increasing urbanisation are not limited to the UK. In 2008, the United Nations reported that for the first time in history more than $50 \%$ of the world's population were living in urban settlements. ${ }^{31}$ Combined with the rapidly increasing worldwide prevalence of chronic kidney disease, driven by an explosion in the prevalence of hypertension, obesity and diabetes in the developing world, this means that the message highlighted here will be of great interest to nephrologists, health economists and patients across the globe.

In conclusion, it is clear that home-based methods of RRT, although widely agreed to be both largely better for patients and more cost effective, are severely underused in the UK. In particular, we highlight that environmental factors are a huge barrier to the start of HHD and even PD, particularly in inner city areas, and to a lesser extent nationwide. Housing resources and the current shortfall in planned affordable house building will continue to compromise our ability to offer home dialysis therapies for the foreseeable future with consequent increase in RRT costs and the removal of patient choice in many instances.

Contributors MY and MR conceived the idea of the study. MY, MR and SF were responsible for the design of the study. SF and KM were responsible for undertaking the data analysis and produced the tables and graphs. SF, KM, MR and MY provided input into the data analysis. The initial draft of the manuscript was prepared by SF and was then circulated repeatedly among all authors for critical revision. TL and MS were responsible for the acquisition of the data, with additional design and production of the HHSRS checklist by TL. MY, SF, KM and MR contributed to the interpretation of the results.

Funding This research received no specific grant from any funding agency in the public, commercial or not-for-profit sectors.

Competing interests None.

Provenance and peer review Not commissioned; externally peer reviewed.

Data sharing statement No additional data are available.

\section{REFERENCES}

1. The Renal Association UK Renal Registry Thirteenth Annual Report 2010.

2. National Institute for Clinical Excellence. Guidance on home compared with hospital hemodialysis for patients with end-stage renal failure. Technology Appraisal Guideline No 48, 2002. http:// 
www.nice.org.uk/nicemedia/pdf/HvH full guidance.pdf (accessed Sept 2012).

3. Blagg CR. Home hemodialysis; 'home, home, sweet, sweet home!'. Nephrology 2005;10:206-14.

4. Roderick PJ, Raleigh VS, Hallam L, et al. The need and demand for renal replacement therapy amongst ethnic minorities in England. J Epidemiol Comm Health 1996;50:334-9.

5. Method to Assess Treatment Choices for Home Dialysis (MATCH-D) 2009. http://www.homedialysis.org (accessed Sept 2012).

6. Housing Health and Safety Rating System (HHSRS) [England] Regulations 2005. http://www.communities.gov.uk/documents/ housing/pdf/150940.pdf (accessed Sept 2012).

7. Baillod RA, Comty C, llahi M, et al. Overnight hemodialysis in the home. Proc Eur Dial Transplant Association 1965;2:99-103.

8. Nose (Hokkaido group). Home hemodialysis: a crazy idea in 1963: a memoir. ASAIO J 2000;46:13-17.

9. Boen ST, Mulinari AS, Dillard DH, et al. Periodic peritoneal dialysis in the management of uremia. Trans ASAIO 1962;8:256-65.

10. Baboolal K, McEwan P, Sondhu S, et al. The cost of renal dialysis in a UK setting - a multicentre study. Nephrol Dial Transplant 2008;23:1982-9.

11. Blagg CR. Home hemodialysis. BMJ 2008;336:3

12. Morris PL, Jones B. Life satisfaction across treatment methods for patients with end-stage renal failure. Med J Aust 1989;150:428-32.

13. McFarlane PA, Bayoumi AM, Pierratos A, et al. The quality of life and cost utility of home nocturnal and conventional in-center hemodialysis. Kidney Int 2003;64:1004-11.

14. Connor A, Lillywhite R, Cooke MW. The carbon footprints of home and in-center maintenance hemodialysis in the United Kingdom). Haemodial Int 2011;15:39-51.

15. Saber E, Nithsch D, Descoeudres C, et al. Outcomes of home hemodialysis patients: a case-cohort study. Nephrol Dial Transplant 2005;20:604-10.

16. Chan CT, Jain V, Picton $P$, et al. Nocturnal hemodialysis increases arterial baroreflex sensitivity and compliance and normalizes blood pressure of hypertensive patients with end-stage renal disease. Kidney Int 2005;68:338-44.

17. Culleton BF, Walsh M, Klarenbach SW, et al. Effect of frequent nocturnal hemodialysis vs conventional hemodialysis on left ventricular mass and quality of life. A randomized controlled trial. J Am Med Assoc 2007;298:1291-9.

18. The FHN Trial Group. In-center hemodialysis six times per week versus three times per week. N Engl J Med 2010;363:2287-300.
19. Schwartz DI, Pierratos A, Richardson RMA, et al. Impact of nocturnal home hemodialysis on anemia management in patients with end-stage renal disease. Clin Nephrol 2005;63:202-8.

20. Achinger S, Ayus JC. The role of daily dialysis in the control of hyperphosphatemia. Kidney Int 2005;67:S28-32.

21. Pierratos A. Effect of therapy time and frequency on effective solute removal. Semin Dial 2001;14:284-8.

22. Department of Health. The expert patient: a new approach to chronic disease management in the 21st century. 2001. http://www.dh.gov. uk/en/Publicationsandstatistics/Publications/PublicationsPolicy AndGuidance/DH_4006801 (accessed Sept 2012).

23. Chesterton LJ, Fluck RJ. Home dialysis therapies-peritoneal dialysis and home haemodialysis working together. Eur Nephrol 2011:5:41-4.

24. 'Statutory Homelessness-Households in Temporary accommodation in London and England at the end of each Quarter 1998-2011.' Department for Communities and Local Government Live Tables. December 2011. http://www.communities.gov.uk/documents/ statistics/pdf/2102020.pdf (accessed Sept 2012).

25. 'English Housing Survey-Headline Report 2009-2010.' Department for Communities and Local Government. February 2011. http://www. communities.gov.uk/documents/statistics/pdf/1851086.pdf (accessed Sept 2012)

26. 'Crowded Houses-Overcrowding in London's Social Rented Housing' London Assembly. March 2011. http://www.london.gov.uk/ moderngov/mgConvert2PDF.aspx?ID=3149 (accessed Sept 2012)

27. 2001 Census Office of National Statistics. http://www.ons.gov.uk/ ons/guide-method/census/census-2001/index.html (accessed Nov 2012).

28. 'A Decent Home: Definition and Guidance for Implementation' Department for Communities and Local Government. June 2006. http://www.communities.gov.uk/documents/housing/pdf/138355.pdf (accessed Sept 2012).

29. 'English Housing Condition Survey-Housing Stock Report 2009' Department for Communities and Local Government. November 2011. http://www.communities.gov.uk/documents/statistics/pdf/ 19372481.pdf (accessed Sept 2012)

30. 'English Housing Survey 2010 to 2011; household report'. Department of Communities and Local Government. July 2012 https://www.gov.uk/government/publications/english-housingsurvey-household-report-2010-to-2011 (accessed Nov 2012).

31. Lahariya C. The state of the world population 2007: unleashing the potential of urban growth. Indian Pediatr 2008;45:481-2 